\title{
Uma proposta de ensino interdisciplinar
}

\section{An interdisciplinary teaching proposal}

\author{
Luiz Felipe Farias Mota ${ }^{1}$ \\ Vitor Amorim ${ }^{2}$ \\ Rui Manoel de Bastos Vieira ${ }^{3}$
}

\begin{abstract}
Resumo: Este trabalho foi desenvolvido a partir de uma Iniciação Científica, sua aplicabilidade está voltada para um ensino de interdisciplinar capaz de integrar conceitos de física e música. Nossa proposta tem como objetivo apresentar uma proposta de ensino, na qual focamos em "no que ensinar", "como ensinar" e "por que ensinar". A proposta de ensino sugere a utilização práticas experimentais em sala de aula, para compô-las apresentamos os seguintes materiais disponíveis: um xilofone, um piano digital acompanhado de um conjunto de 4 teclados fabricados de papel, porém pintados com materiais diferentes, além de teclas "avulsas" constituídas de diversos materiais. A proposta tem a intenção de tornar evidente o diálogo entre o estudo de ondulatória e a produção de sons no xilofone e no piano digital, e dessa forma reforçar a ideia de que o saber se constitui como um todo e não de modo fragmentado.
\end{abstract}

Palavras-chave: Física e Música. Instrumentos musicais. Interdisciplinar. Aprendizagem significativa.

Abstract: This paper was developed from a Scientific Initiation, the applicability is aimed at an interdisciplinary teaching capable integrate concepts of physics and music. Our proposal aims to present a teaching proposal, we focus on "What teach", "how to teach" and "Why teach". This teaching proposal suggests utilizing experimental practices in classroom, to complete them we present the following available materials: a xylophone, a digital piano with a group of 4 keyboards made of paper, but each keyboard is painted with different materials, and some "separate" keys, those are made by diverse materials. The proposal is intended to become evident the dialogue between the studies of wave motion and the sound production in the xylophone and the digital piano, and in this way to reinforce the notion that the knowledge is constituted as a whole and not in a fragmented way.

\footnotetext{
${ }^{1}$ Licenciatura em Ciências, UNIFESP, felipe.mota@unifesp.com.br

${ }^{2}$ Mestrado em Ensino de Ciências e Matemática, ICAQF, UNIFESP, vitor.amorim@unifesp.br

${ }^{3}$ Doutor, UNIFESP, rui.vieira@unifesp.br
}

Recebido em 23/01/2022

Aprovado em 10/02/2022

Sistema de Avaliação: Double Blind Review

OPEN ACCESS 


\section{REVISTA MULTIDISCIPLINAR \\ ISSN 1809-1628

Keywords: Physics and music. Musical Instruments. Interdisciplinary. Substantial apprenticeship.

\section{Introdução}

Segundo Hazen (2006), a física é considerada pelos alunos como uma das disciplinas mais desinteressantes, visto que o ensino dessa disciplina perdeu seu caráter lúdico e experimental. Da mesma maneira que Roederer (2002) e Rossing (1990), acreditamos que nesse sentido é importante a elaboração de projetos interdisciplinares, capazes de conectar os conhecimentos físicos aos assuntos que são de interesse dos alunos e que fazem parte do seu cotidiano.

Para Fazenda (1994) e Pombo (2004), a realização de atividades interdisciplinares levam os alunos a observarem os conteúdos das disciplinas de uma forma diferente, analisando as convergências entre os assuntos e estabelecendo ligações entre os saberes, dessa forma, estimulando o aprendizado significativo.

Portanto, quando uma proposta interdisciplinar é capaz de conectar a música à ciência, ela facilita a aprendizagem e contribui para melhorar a qualidade do ensino. De acordo com Fazenda (1994), a interdisciplinaridade possibilita o diálogo com as diversas ciências, tornando viável entender o saber como um todo e não fragmentado.

Para Araújo \& Abib (2003), os livros didáticos disponíveis para o trabalho dos professores, consistem somente em orientações, que seguem e reforçam uma abordagem tradicional de ensino, em que o conteúdo científico é acompanhado apenas de demonstrações fechadas, tal abordagem é distante do cotidiano dos alunos, dessa forma, afetar e converter as concepções espontâneas dos alunos em conhecimento científico se torna uma tarefa muito complexa e difícil de ser alcançada.

Partindo destes princípios, este trabalho tem como objetivo apresentar uma proposta de ensino, que pode ser aplicada em uma sala de aula, a aplicação desta proposta tem a intenção de proporcionar às crianças e aos adolescentes um contato mais próximo com a tecnologia, com a música e suas propriedades. Da mesma maneira que Snyders (1992), entendemos que esta abordagem pode contribuir para que os estudantes tenham acesso ao que o autor chama de Cultura Elaborada.

Também, a atividade desenvolvida através da proposta de ensino tem o potencial de contribuir para estudos de conceitos científicos, em especial no ensino de física, além de 
trazer uma atividade prática que desperta o interesse dos alunos, porque como Moraes (2008) concordamos que as atividades práticas e experimentação são de suma importância nas escolas para o ensino das Ciências porque elas "possibilitam aos alunos uma aproximação do trabalho científico e melhor compreensão dos processos de ação das ciências."

Dessa forma, além de proporcionar uma atividade prática aos alunos, a proposta traz a integração entre física, música e tecnologia, para dentro do contexto escolar de forma a abordar conceitos relacionados à física que estão interligados na confecção e na característica de um xilofone, como frequência, intensidade, duração, timbre, propagação do som, ressonância, vibração. Tais abordagens, se caracterizam como uma ausência no ensino, como foi apontado por Mercado (2002, p.11), “o reconhecimento de uma sociedade cada vez mais tecnológica deve ser acompanhado da conscientização da necessidade de incluir nos currículos escolares as habilidades e competências para lidar com as novas tecnologias".

\section{A Música e as Ciências Naturais}

Segundo Ferreira \& Silva (2019), a música é uma manifestação artística, a qual constitui um conjunto de sons sucessivos e simultâneos, os quais ao chegar aos ouvidos humanos, passam por processo de organização transformando-se na música. De acordo com Bréscia (2003), a música está presente na história da humanidade, dessa forma ela representa uma linguagem universal.

A física e a música são duas áreas do conhecimento que possuem conexão, por exemplo, as ondas sonoras são ondas mecânicas longitudinais, cuja faixa de frequências audíveis para o ser humano corresponde aos limites entre $20 \mathrm{~Hz}$ e $20 \mathrm{kHz}$, estes sons são de variados tipos e suas características dependem da fonte sonora, sendo possível descrever e representar o fenômeno ondulatório por meio de expressões matemáticas, gráficos e tabelas (NUSSENZVEIG, 2014). Por outro lado, as características deste fenômeno são representadas pela notação musical por meio de representações gráficas, chamada de partitura, portanto, vemos que tanto a física quanto a música representam o mesmo fenômeno sonoro, porém de maneiras diferentes.

Ao ouvirmos atentamente o trecho de uma obra musical, podemos perceber uma sucessão de sons distinguíveis pelas durações, intensidades, timbres e alturas relativas, dessa 
forma, ao analisarmos o som no contexto da física e da música, também devemos ser capazes de observar tais características a partir da representação do som.

As figuras musicais representam unidades de tempo, embora as relações entre as diferentes figuras são dadas por razões fixas, elas não têm necessariamente um valor fixo, a figura nomeada por semibreve é a de maior valor temporal, as seguintes figuras, mínimas, semínimas, colcheia, semicolcheia, fusa e semifusa, são frações da semibreve, por exemplo, uma semibreve é o equivalente à quatro semínimas ou trinta e duas fusas.

Uma outra qualidade do som é a frequência, que é responsável por classificar os sons como agudos ou graves, neste caso as ondas sonoras com frequências baixas são mais graves do que as de frequências mais altas. Do ponto de vista da simbologia musical, as frequências das notas são representadas escrevendo-se as figuras de valores no pentagrama, esta estrutura é formada por um conjunto de cinco linhas e quatro espaços, dessa forma, as notas escritas mais acima representam frequências maiores, notas escritas mais abaixo representam frequências menores, e o nome das notas está diretamente relacionado com a frequência e a clave do respectivo compasso.

Outra característica das ondas sonoras é a intensidade, que é responsável por classificar os sons como fortes e fracos. Do ponto de vista musical, as relações entre os sons fracos e fortes possui a função de realizar a dinâmica musical, as simbologias utilizadas para indicar tais relações são pp, $\mathrm{p}, \mathrm{mp}, \mathrm{mf}, \mathrm{f}$ e ff, elas derivam do italiano, e significam respectivamente, pianíssimo (muito fraco), piano (fraco), mezzo piano (moderadamente fraco), mezzo forte (moderadamente intenso), forte (intenso) e fortíssimo (muito intenso).

Outro aspecto do som a ser analisado é o timbre, que é a possibilidade de distinção entre sons emitidos por diferentes instrumentos, isto ocorre porque o som é uma composição de ondas sonoras, a presença dos harmônicos e suas intensidades relativas na composição de cada nota são diferentes para sons produzidos por fontes diferentes, no caso dos instrumentos a geometria e o material determinam como as frequências fundamentais se manifestarão na emissão de cada som.

\section{A Física e a Música em ambiente escolar}


Após tratarmos cientificamente os temas concernentes à música, chegou o momento de refletirmos nas vantagens e nas formas que devemos aplicar a física e a música em uma proposta de ensino dentro do ambiente escolar.

Observando as reflexões tratadas até então, podemos afirmar que a música é um elemento presente na cultura humana, de acordo com Ferreira \& Silva (2019), ao analisarmos os efeitos dela, quando utilizada em ambiente escolar, observa-se que propicia a abertura de canais sensoriais, facilita a expressão de emoções, amplia a cultura geral e contribui para a formação integral do ser.

Considerando que, a música é uma forma de expressão humana, afirma-se que sua presença é importante no contexto educacional, pois proporciona um aprendizado interdisciplinar e lúdico possibilitando um aprendizado significativo, para Nogueira (2000), é através de uma aprendizagem significativa que os conceitos abordados são assimilados pelos alunos.

Com relação à física, sabe-se que em alguns casos, as aulas teóricas não são ministradas de forma adequada, por consequência, essas aulas tornam-se desmotivantes e ineficientes para o aprendizado dos alunos e, de fato, eles sentem-se desestimulados ao estudo, segundo Hazen (2006), ela é apontada pelos alunos como uma das disciplinas mais desinteressantes, .Uma maneira de tornar as aulas de física mais interativas e atrativas é através do uso de experimentos, segundo Araújo \& Abib (2003), a utilização de atividades experimentais como uma estratégia de ensino, tem sido comprovado como uma das maneiras de diminuir as dificuldades de se aprender e de ensinar física de forma significativa e consistente, tornando a aula dinâmica e prática.

Portanto, conforme o proposto pelos referenciais teóricos, este trabalho buscou desenvolver uma proposta de ensino dinâmica, tendo como foco a interdisciplinaridade entre a física e a música, buscando proporcionar um enfoque investigativo. Da mesma maneira que Carrascosa (2006), acredita-se que os alunos devem participar ativamente dos processos de experimentações, e que a aprendizagem adquirida sirva para a vida do aluno como um todo, não apenas para sua vida escolar.

O interesse do trabalho é utilizar a proposta de ensino, como artificio para a construção de um conhecimento mais próximo da realidade do aluno, influenciando o aluno a ter atitudes positivas e ativas no decorrer do processo de ensino-aprendizagem, para Araújo \& Abib (2003), o estímulo da participação ativa dos alunos, aumenta a probabilidade da 
elaboração de conhecimentos, e o desenvolvimento de habilidades, atitudes e competências relacionadas ao fazer e entender a Ciência.

\section{A Física do xilofone}

Depois da exposição interdisciplinar dos conceitos de física e de música, agora iremos explicar o que é o xilofone. O xilofone é um instrumento musical de percussão, fabricado de placas de madeira e organizado de forma que as teclas fiquem dispostas uma ao lado da outra, de forma que as notas musicais crescem com relação à frequência da esquerda para a direita. As teclas são apoiadas sobre um suporte de madeira e elas são percutidas utilizando-se baquetas, cujas cabeças podem ser feitas com madeira dura, borracha ou outros materiais.

Um dos produtos desta proposta foi a fabricação de um xilofone artesanalmente, através do uso de materiais acessíveis, as teclas do xilofone foram esculpidas através do uso da esmerilhadeira, sendo assim o designe delas ficou com uma estética mais rústica, mas mesmo que ele não seja visualmente tão sofisticado quanto um xilofone profissional, conseguimos preservar as qualidades sonoras semelhantes à de um instrumento mais elaborado, visto que, como demonstrado nas fórmulas apresentados nas imagens abaixo, a modelagem matemática utilizada para compreender o comportamento das teclas do ponto de vista musical, foi capaz de comportar objetos com superfícies irregulares.

Conforme verificado nos tópicos anteriores, antes da fabricação dos materiais didáticos, realizamos uma revisão bibliográfica sobre a acústica e a resistência dos materiais, ou seja, investigamos a respeito das ondas sonoras e dos padrões produzidos através da propagação do som nos materiais utilizados na fabricação dos instrumentos.

Nesse contexto, o som que escutamos do xilofone, se deve pelo fato de que ao atingir uma das teclas de madeira com a baqueta, são provocadas vibrações em todo o material constituinte desta tecla. As vibrações, podem ser interpretadas como ondas estacionárias, que são resultantes do comportamento do material após o choque entre as baquetas e uma das teclas.

A formação destas ondas estacionárias se manifestam através do corpo da tecla, conforme demonstrado na figura 1: 
Figura 1: Formação de ondas nas teclas do xilofone

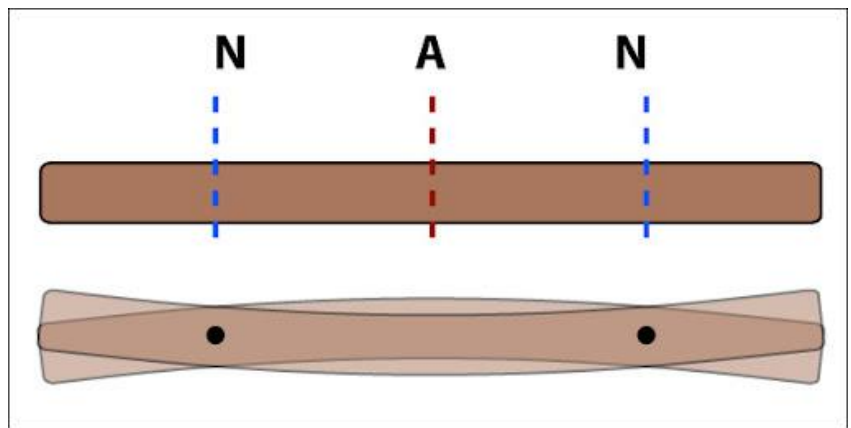

Fonte: http://www.hopestreetmarimba.com/a-driftwood-marimba-on-the-beach-of-improbability/

Figura 2: Xilofone confeccionado

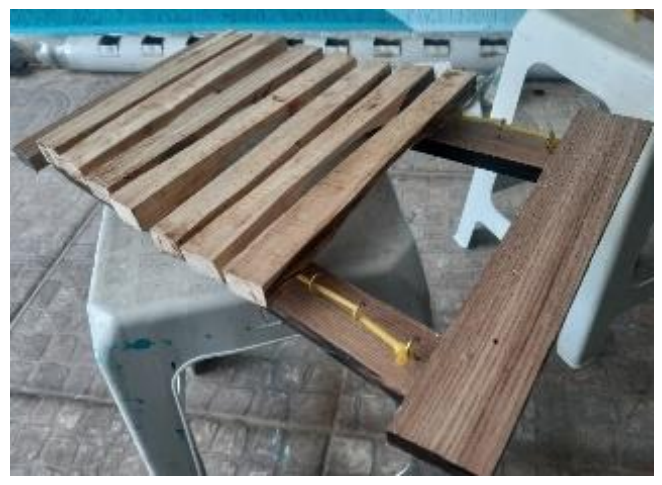

Fonte: Desenvolvido pelo autor

Através da figura 2, é visível que as teclas são apenas apoiadas e não presas, tal configuração possibilita que as teclas vibrem livremente ao serem atingidas pela baqueta. Portanto, ao vibrar uma das teclas são produzidos nós e antinós, conforme podemos verificar na figura 1. Além disso, ao apoiar as teclas no suporte, devemos apoiá-las exatamente nos locais em que se formam os nós, caso contrário pode atrapalhar a vibração das teclas e consequentemente prejudicar o som emitido por elas.

O som emitido por cada tecla tem relação direta com propriedades físicas da própria tecla, como por exemplo, o comprimento, a espessura, a densidade e a elasticidade linear do material (módulo de Young), a equação representada pela figura 3 expressa o cálculo, que é capaz de nos fornecer o valor da frequência emitida por uma tecla de xilofone, quando ela é 
atingida por uma baqueta, esta equação leva em conta todas as "variáveis" que foram mencionadas acima.

Figura 3: Equação da frequência de uma tecla de xilofone

$$
f=1.028 \frac{a}{L^{2}} \sqrt{\frac{Y}{d}}
$$

Fonte: http://www.hopestreetmarimba.com/a-driftwood-marimba-on-the-beach-of-improbability/

$\mathrm{Na}$ equação mostrada na figura 3 temos os seguintes elementos, "a" representa a espessura do material, "L" é o comprimento, "Y" é o módulo de Young, "d" é a densidade do material, "1,028" é uma constante e f é a frequência ao qual a tecla vibrará ao ser atingida.

Dessa forma, podemos dizer que em um conjunto de teclas, as quais possuem o mesmo material, ou seja, apresentam o mesmo módulo de Young, a mesma densidade e a mesma espessura, porém variam apenas o comprimento, as teclas que possuírem o maior comprimento serão aquelas que ao serem atingidas apresentarão uma frequência menor, portanto serão mais "graves".

Por outro lado, ao considerarmos o mesmo conjunto de teclas, porém ao invés de variarem o comprimento elas variem somente a espessura, as teclas que possuírem a maior espessura serão aquelas que ao vibrarem terão uma frequência maior, ou seja, serão mais "agudas".

Analogamente, ao considerarmos um conjunto de teclas que variam somente com relação ao módulo de Young, temos que as teclas que apresentarem um material que possui um valor superior desta variável terão uma frequência maior do que as demais, e em contrapartida, ao fazermos esta relação considerando apenas a densidade como variável, as teclas que forem constituídas de um material que possui a maior densidade dentre as demais do conjunto analisado, essas apresentarão uma frequência resultante menor. 


\section{REVISTA MULTIDISCIPLINAR \\ ISSN 1809-1628 \\ HUMANIDADESE TECNOLOGIAS (FINOM)}

Portanto, através da equação representada pela figura 4 conseguimos calcular os comprimentos de cada tecla do xilofone que foi fabricado pela proposta, as teclas fabricadas estão representadas abaixo, pela figura 4:

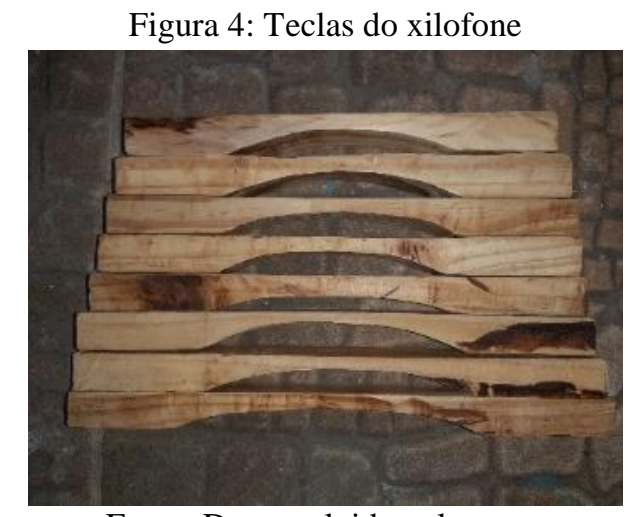

Fonte: Desenvolvido pelo autor

O processo de afinação das teclas consiste em lixar sua parte inferior, dessa forma, na medida em que se retira o material através do desbaste, menor fica a frequência correspondente a esta tecla.

O procedimento de lixar a tecla é vantajoso do ponto de vista do som emitido pelo instrumento, pois ao desbastar somente no centro do material, as partes mais "pesadas do material" ficam localizadas nas extremidades da tecla, dessa maneira, temos como resultado uma onda de maior amplitude e consequentemente o som emitido terá maior intensidade.

O xilofone de nossa proposta é artesanal, dessa maneira, o design das teclas possui uma estética mais rústica, mas apesar de não ser visualmente tão sofisticado quanto um xilofone profissional, as qualidades sonoras são semelhantes à de um instrumento mais elaborado.

\section{Proposta de ensino}

Em uma perspectiva educacional, com o intuito de desenvolver o senso criativo e investigativo dos alunos, podem ser disponibilizadas teclas "avulsas" produzidas a partir de materiais variados, dentre eles temos madeira (Pinus strobus), canos de PVC e varão de cortina, com isso os alunos possuiriam uma variedade de teclas à disposição. Para esta atividade investigativa, os alunos desenvolveriam uma explicação capaz de justificar o motivo 
pelo qual as teclas soam com frequência diferente, sabendo que algumas delas possuem o mesmo comprimento, mas são confeccionadas de materiais diferentes.

Uma outra atividade que pode ser desenvolvida pela proposta é referente à construção de um piano digital, utilizando-se Arduino, na qual é programado em linguagem $\mathrm{C}++$, além disso, todos os alunos devem produzir quatro tipos diferentes de teclados na folha sulfite, a variante entre eles é o material utilizado para pintá-los, sabendo que um dos teclados deve ser pintado somente com grafite, após terminada esta etapa, todos deveriam constatar em qual dos teclados ocorre a produção de som.

A atividade científica apresentada pela proposta de ensino, possibilita aos alunos a construção de muitas competências, visto que ela propõe a manipulação, o questionamento, o direito ao tateamento e ao erro, a observação, expressão, comunicação, verificação, análise e síntese (CHARPAK, 1996, p.26-27). A partir deste ponto de vista, o aluno não se limita apenas ao trabalho de manipulação e observação, pois o caminho necessário para a resolução de problemas exige também reflexões, relatos, discussões, ponderações e explicações, este caminho para esta resolução corresponde a características de uma investigação científica (CARVALHO et al., 1999, p.31). Também, sabendo que "todo conhecimento é resposta a uma questão" (BACHELARD, 1996) e que a proposta de ensino investigativo vinculada aos experimentos foi cuidadosamente elaborada, é importante ressaltar que as atividades investigativas se fundamentam na ação dos alunos, não se limitando à simples manipulação ou observação (VIEIRA, 2005).

O instrumento escolhido para desenvolvimento da atividade é de fácil manuseio, aprendizagem, e de simples confecção, entretanto os conceitos científicos envolvidos na preparação do material não são simples, pois envolve muitos fatores para que o instrumento emita sons agradáveis, como por exemplo, o material constituinte do copo; o líquido que colocado dentro do copo, bem como sua densidade e volume.

O objeto instrumental, tem a função de aproximar os alunos de atividades que envolvam ciências e tecnologia, e proporcionando-os à realização de uma atividade musical. 


\section{Considerações finais}

O trabalho apresentado por este artigo, além de apresentar as reflexões de física e da música, visa mostrar uma proposta de ensino interdisciplinar, cujos objetivos são claros e definidos, os quais possam ser efetivados no cotidiano escolar. É importante, que a educação faça sentido para a vida do aluno, tanto no ambiente escolar, como em sua vida particular.

Com base neste trabalho, pode-se compreender que a música é uma ferramenta que está presente na vida de todos os alunos, sendo assim, ela constitui uma ferramenta responsável pela formação integral do ser humano.

Encontramos na proposta interdisciplinar entre a música e o ensino de física, um instrumento forte para poder alcançar os objetivos pedagógicos. É importante aplicar práticas experimentais, utilizando-se abordagens de cunho investigativo, pois conforme demonstrado neste trabalho, essa estratégia pedagógica proporciona ao aluno a capacidade de conciliar o seu cotidiano à teoria de forma prática, incentivando-os a participarem mais das aulas, além de despertar o interesse pela ciência.

Ademais, é necessário estar sempre buscando um melhor aproveitamento dos benefícios que a música pode proporcionar, para isso é necessário elaborar propostas pedagógicas capazes de incluir a música como um instrumento de trabalho.

Finalmente, esperamos que a proposta de ensino apresentada por este trabalho tenha servido de inspiração para que ela possa ser aplicada em ambiente escolar e que também tenha incentivado o desenvolvimento de mais propostas de ensino capazes de envolver a música e atividades experimentais como recursos didáticos.

\section{Referências}

ARAÚJO, M.S.T. de; ABIB, M.L.V. dos S. Atividades Experimentais no Ensino de Física: Diferentes Enfoques, Diferentes Finalidades. Revista Brasileira de Ensino de Física, v. 25, n. 2, p. 176 - 194, 2003.

BACHELARD, G. A formação do espírito científico: contribuição para uma psicanálise do conhecimento. Contraponto. Rio de Janeiro, 1996.

BRÉSCIA, Vera Lúcia Pessagno. Educação Musical: bases psicológicas e ação preventiva. São Paulo: Átomo, 2003.

CARRASCOS, A, J.; PÉREZ, D.G.; VILCHES, A.; VALDÉS, P. Papel de la actividad 


\section{REVISTA MULTIDISCIPLINAR \\ ISSN 1809-1628

experimental en la educación científica. Caderno Brasileiro do Ensino de Física - Vol. 23, n. 2: p. 157-181, 2006.

CAVALCANTE, João et al. FÍSICA E MÚSICA: UMA PROPOSTA

INTERDISCIPLINAR. Revista Areté | Revista Amazônica de Ensino de Ciências, [S.1.], v. 5, n. 9, abr. 2017. ISSN 1984-7505. Disponível em:

<http://periodicos.uea.edu.br/index.php/arete/article/view/50>. Acesso em: 09 dez. 2021.

FAZENDA, I. C. A. Interdisciplinaridades: história, teoria e pesquisa. Campinas: Papirus, 1994.

FERREIRA, J. F., SILVA, J. F. A importância da música no contexto da educação especial. Humanidades \& tecnologia em Revista (FINOM) - ISSN: 1809-1628. Ano XIII, vol.16 - Jan - Dez 2019.

HAZEN, R. M. Física Viva. v. 2, Rio de Janeiro: LTC, 2006.

KRUMMENAUER, W. L., et al. O uso de instrumentos musicais como ferramenta motivadora para o ensino de acústica no ensino médio. Física na Escola. v.10. n.2, 2009.

LEHRER, J. The future of science is art? Disponível em: https://environment.lafayette.edu/2010/04/05/the-future-of-science-is-art/ . Acesso em: 6 de dezembro de .2021.

MERCADO, L. P. L. Formação Docente e novas tecnologias. In: MERCADO, L. P. L. (org.). Novas Tecnologias na educação: reflexões sobre a prática. Maceió: EDUFAL, 2002. p. 11-28.

MORAES, R. Construtivismo e ensino de ciências: reflexões epistemológicas e metodológicas. 3. ed. Porto Alegre: EDIPUCRS, 2008.

NOGUEIRA, J. de S.; RINALDI, C.; FERREIRA, J.M.; PAULO, S.R. de. Utilização do Computador como Instrumento de Ensino: Uma Perspectiva de Aprendizagem Significativa. Revista Brasileira de Ensino de Física, v. 22, n. 4, p. 517 - 522, 2000

NUSSENZVEIG, H. M. Curso de Física Básica, 2: fluidos, oscilações e ondas, calor. 5. ed. São Paulo: Blucher, 2014.

POMBO, O. Interdisciplinaridade: Conceitos, problemas e perspectivas. Revista Brasileira de Educação Médica. Rio de Janeiro, v. 1, no 30, 2004.

ROCHA, J.F.M. (org.). Origens e evolução das ideias da Física. Salvador: EDUFBA. p. 2136.2002 .

ROEDERER, J. G. Introdução à Física e Psicofísica da Música. São Paulo: Edusp, 2002.

ROSSING, T. D. The Science of Sound. EUA: Addison-Wesley, 1990. 
VIEIRA, R. M. B.; SANTOS, E. I.; PIASSI, L. P. C.. L.Y.R.A. - Laboratory of Inquiring in Robotics and Astronautics. CONEXÃO CIÊNCIA (ONLINE), v. 12, p. 210-216, 2017.

SNYDERS, G. A Alegria na Escola. São Paulo: Manole, 1988. 